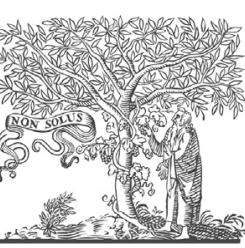

\title{
Hypertension, preeclampsia and eclampsia among HIV-infected pregnant women from Latin America and Caribbean countries ${ }^{\text {ir }}$
}

\author{
Elizabeth Stankiewicz Machado ${ }^{\mathrm{a}, *}$, Margot R. Krauss ${ }^{\mathrm{b}}$, \\ Karen Megazzini ${ }^{\mathrm{b}}$, Conrado Milani Coutinho ${ }^{\mathrm{C}}$, \\ Regis Kreitchmann ${ }^{d}$, Victor Hugo Melo ${ }^{e}$, \\ José Henrique Pilotto ${ }^{f}$, Mariana Ceriotto ${ }^{g}$, Cristina B. Hofer ${ }^{a}$, \\ George K. Siberry ${ }^{h}$, D. Heather Watts ${ }^{h}$, for the NICHD \\ International Site Development Initiative (NISDI) Pediatric \\ Protocol
}

\author{
a Instituto de Puericultura e Pediatria Martagão Gesteira, Universidade Federal do Rio de Janeiro, Rio \\ de Janeiro, Brazil \\ ${ }^{\mathrm{b}}$ Westat, Rockville, MD, USA \\ ' Hospital das Clínicas da Faculdade de Medicina de Ribeirão Preto, Universidade de São Paulo, Brazil \\ 'Irmandade da Santa Casa de Misericordia de Porto Alegre, Porto Alegre, RS, Brazil \\ e Faculdade de Medicina, Universidade Federal de Minas Gerais, Belo Horizonte, Brazil \\ f Laboratório de AIDS e Imunologia Molecular, Fiocruz-IOC \& Hospital Geral de Nova Iguaçu, Rio de \\ Janeiro, Brazil \\ ${ }^{\mathrm{g}}$ Infectious Diseases Unit, Dr. Cecilia Grierson Hospital, Buenos Aires, MD, Argentina \\ ${ }^{\mathrm{h}}$ Maternal and Pediatric Infectious Disease Branch, NICHD/NIH, Bethesda, MD, USA
}

Accepted 16 December 2013

Available online 23 January 2014

KEYWORDS

HIV-infected women;

Pregnancy;

Hypertensive disorders;
Summary Objectives: To evaluate the incidence of and risk factors for hypertensive disorders in a cohort of HIV-infected pregnant women.

Methods: Hypertensive disorders (HD) including preeclampsia/eclampsia (PE/E) and pregnancy induced hypertension, and risk factors were evaluated in a cohort of HIV-infected pregnant

\footnotetext{
The findings and conclusions in this report are those of the authors and do not necessarily represent the views of the US National Institutes of Health or the Department of Health and Human Services.

* Corresponding author. IPPMG/UFRJ, Serviço de Pré-Natal, Av. Bruno Lobo, 50, Cidade Universitária, Rio de Janeiro, RJ 21941-912, Brazil. Tel./fax: +55212562 2526 .

E-mail address: emachado@infolink.com.br (E.S. Machado).
} 
Preeclampsia; Eclampsia women from Latin America and the Caribbean enrolled between 2002 and 2009. Only pregnant women enrolled for the first time in the study and delivered at $\geq 20$ weeks gestation were analyzed.

Results: HD were diagnosed in $73(4.8 \%, 95 \% \mathrm{Cl}: 3.8 \%-6.0 \%)$ of 1513 patients; 35 (47.9\%) had $P E / E$. HD was significantly increased among women with a gestational age-adjusted body mass index $(\mathrm{gBMl}) \geq 25 \mathrm{~kg} / \mathrm{m}^{2}(\mathrm{OR}=3.1 ; 95 \% \mathrm{Cl}: 1.9-5.0)$, hemoglobin $(\mathrm{Hg}) \geq 11 \mathrm{~g} / \mathrm{dL}$ at delivery $(\mathrm{OR}=2.1 ; 95 \% \mathrm{Cl}: 1.2-3.6)$ and age $\geq 35$ years $(\mathrm{OR}=1.8 ; 95 \% \mathrm{Cl}: 1.1-3.2) . \mathrm{PE} / \mathrm{E}$ was increased among women with a gBMl $\geq 25 \mathrm{~kg} / \mathrm{m}^{2}(\mathrm{OR}=3.0 ; 95 \% \mathrm{Cl}: 1.5-6.0)$ and $\mathrm{Hg} \geq 11 \mathrm{~g} /$ $\mathrm{dL}$ at delivery $(\mathrm{OR}=2.8 ; 95 \% \mathrm{Cl}: 1.2-6.5)$. A previous history of $\mathrm{PE} / \mathrm{E}$ increased the risk of $\mathrm{PE} / \mathrm{E} 6.7$ fold $(95 \% \mathrm{Cl}: 1.8-25.5)$. HAART before conception was associated with PE/E $(\mathrm{OR}=2.3 ; 95 \% \mathrm{Cl}: 1.1-4.9)$.

Conclusions: HIV-infected women, with a previous history of $\mathrm{PE} / \mathrm{E}$, a $\mathrm{gBMI} \geq 25 \mathrm{~kg} / \mathrm{m}^{2}, \mathrm{Hg}$ at delivery $\geq 11 \mathrm{~g} / \mathrm{dL}$ and in use of HAART before conception are at an increased risk of developing $\mathrm{PE} / \mathrm{E}$ during pregnancy.

(C) 2014 The British Infection Association. Published by Elsevier Ltd. All rights reserved.

\section{Introduction}

The prevention of maternal to child transmission (PMTCT) of HIV has progressed from recommending caesarean section, formula feeding, and treatment with Zidovudine monotherapy, ${ }^{1}$ to additionally, implementing the use of highly active antiretroviral therapy (HAART), which led to transmission rates as low as $1-2 \%{ }^{2}$ In spite of this impressive result, the use of HAART during pregnancy has been related to adverse outcomes such as low birth weight, prematurity, ${ }^{3}$ and an increased rate of gestational diabetes was observed comparing data before and after the introduction of HAART. ${ }^{4}$

Hypertensive disorders during pregnancy are a major cause of morbidity and mortality for both mother and child worldwide, and are the number one cause of maternal mortality in some regions in Brazil. ${ }^{5,6}$

However, prevalence data on preeclampsia and eclampsia (PE/E) among HIV-infected women are discrepant. In PACTG 185, where pregnant women were treated predominantly with ZDV during pregnancy, PE was reported to be as low as $2 \%$ among 497 women studied. ${ }^{7}$ In the USA, the rate of PE has remained stable, regardless of the use of HAART during pregnancy. ${ }^{4}$ Other studies have suggested that HIV-infected pregnant women treated with HAART have an increased risk for PE and fetal death. ${ }^{8,9}$ Wimalasundera et al. (2002) showed that the rate of PE in HIVinfected women was not different from that in uninfected pregnant women $(4.2 \%$ vs. $5.6 \%$, respectively), but within the HIV-infected women, the rate of PE in those treated with mono or dual therapy was $0-1 \%$ compared to $11 \%$ among those treated with triple therapy. ${ }^{8} \mathrm{~A}$ probable role of immune reconstitution was implicated in the pathogenesis of PE in women treated with HAART. Suy et al. $(2006)^{9}$ found higher rates of PE among HIV-infected women $(11 / 100$ deliveries) when compared to HIV-uninfected women (2.9/100 deliveries). They also demonstrated that the rate of PE among HIV-infected women increased from $0 \%$ to $11 \%$ in two periods studied, and that this increment was related to use of HAART, especially in those treated with HAART prior to pregnancy.

In Latin America, the prevalence of PE among HIVinfected women has been rarely studied. In one report from Brazil, the rate of PE was $0.8 \%$ in HIV-infected women
(1/123) and $10 \%$ among 1708 HIV-negative women, where $78 \%$ of the first group were treated with HAART. ${ }^{10}$

As more HIV-infected women are being put on HAART earlier in pregnancy it is important to understand the impact of HAART on hypertensive disorders during pregnancy. Our objectives were to determine the prevalence of and risk factors for hypertensive disorders and PE/E among HIV-infected pregnant women in Latin America and to evaluate the impact of HAART in the development of these complications.

\section{Methods}

The Eunice Kennedy Shriver National Institute of Child Health and Human Development (NICHD) International Site Development Initiative (NISDI) and the Perinatal Longitudinal Study in Latin American Countries (LILAC) are two consecutive observational, prospective cohorts of HIVinfected pregnant women enrolled from 2002 to 2009. The main objectives of the NISDI Perinatal and LILAC Studies are to describe utilization of interventions for PMTCT of HIV, rates of mother-to-child infection, and to characterize adverse events associated with receipt of and exposure to ARVs. ${ }^{11}$

The protocols were approved by the ethics committee review board in each clinical site enrolling subjects, the sponsoring institution (NICHD), and the data management and statistical center (Westat). Clinical, immunologic, and virologic characteristics of the women were assessed at enrollment, during pregnancy, at the time of hospital discharge after delivery, and at the 6-12 week postpartum visit. Maternal history of substance use during the index pregnancy was ascertained through patient interview at enrollment. Maternal clinical disease staging ${ }^{12}$ was performed at each study visit. Gestational age-adjusted maternal BMI (gBMl), an approach to correcting for the weight gain expected to occur during pregnancy, was calculated using a program produced by the Argentinean Ministry of Health. ${ }^{13}$ Women who enrolled with a gBMl $>25$ were considered overweight.

Our study population was restricted to women enrolled in the NISDI Perinatal or LILAC protocols for the first time (second pregnancies on-study excluded), prior to labor and delivery (L\&D), and whose infant were born at $\geq 20$ weeks gestation. Women with pre-existing nephropathy were also 
excluded. HAART was defined as the use of at least three drugs in two different classes. Other non-HAART regimens (mono, dual, triple NRTI) therapy was categorized as "other ARV".

The primary outcome measure of interest was the diagnosis of any hypertensive disorder (HD) after 20 weeks of gestation. This included all cases of pregnancy induced hypertension (PIH) [defined as blood pressure persistently $\geq 140 / 90 \mathrm{mmHg}$ without proteinuria and onset after first 20 weeks gestation with no hypertension prior to pregnancy], $P E$ [defined as blood pressure persistently $\geq 140 / 90$ with: proteinuria of $\geq 1+$ by dipstick, on two occasions, and/or $\geq 300 \mathrm{mg}$ protein in $24 \mathrm{~h}$ urine collection], and eclampsia [defined as seizure during pregnancy in the absence of any underlying known etiology or without any known reason for seizure and no suspicion of epilepsy or trauma]. Previous history of hypertension (not associated with pregnancy), $\mathrm{PIH}$, preeclampsia or eclampsia was obtained at enrollment. Gestational age at enrollment was estimated based on the date of the last menstrual period or any earlier ultrasound dating, if available. Analyses were also done in the subset of participants who experienced PE/E.

\section{Statistical analysis}

Descriptive statistics (frequencies) were used to describe the study population. Bivariate analyses (Fisher's exact test) examined the association of hypertensive disorders (HD) and the subset of PE/E with variables assessed at the time of eligibility for the study.

All covariates with alpha level of 0.2 or lower in bivariate analyses were considered candidates for inclusion in the adjusted models. Logistic regression modeling used forward stepwise, backward elimination. All analyses were conducted using the SAS statistical software, version 9.0 (SAS Institute Inc. Cary, NC).

\section{Results}

Of 1548 women experiencing their first pregnancy on study, thirty-five were excluded; three were lost to follow-up, twenty-one enrolled at the time of L\&D, six delivered at $<20$ weeks gestation, and five for pre-existing nephropathy, leaving 1513 women in the final study population (Fig. 1).

The majority of women were from Brazil (62.5\%). Maternal age ranged from 20 to 34 years old for $77.7 \%$ of the participants, $72.9 \%$ were married or living with a partner, $56.2 \%$ enrolled in the cohort during the third trimester of pregnancy and $86.1 \%$ reported at least one previous pregnancy prior to study enrollment (Table 1$)$.

There were 73 cases of HD: 38 (52.1\%) diagnosed with PIH and 35 (47.9\%) diagnosed with $P E / E$ for a cumulative prevalence for $\mathrm{HD}$ of $4.8 \%(95 \% \mathrm{Cl}: 3.8 \%-6.0 \%)$ and $2.3 \%$ (95\% Cl: $1.7 \%-3.2 \%)$ for PE/E. Three women developed eclampsia, but none died. Among those diagnosed with $\mathrm{PIH}$, $81.6 \%(31 / 3)$ had documented normal blood pressures at the time of enrollment prior to their diagnosis of hypertension.

On bivariate analyses, HD was significantly more frequent among women who were gainfully employed, married or living with a partner, gBMI $\geq 25$ at enrollment, and with a higher hemoglobin value $(\geq 11 \mathrm{~g} / \mathrm{dL})$ at

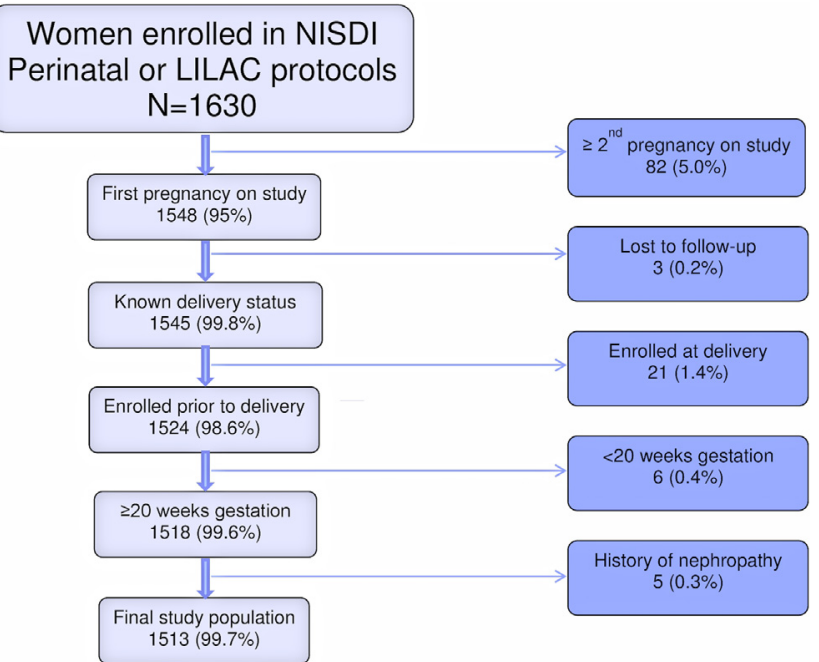

Figure 1 Derivation of study population.

enrollment and following delivery. While use of any antiretroviral therapy (ARV) at conception was not significantly associated with HD, being on HAART or any PI regimen at conception was associated with HD ( $p=.04)$ (Table 2).

On bivariate analyses, the association of $\mathrm{PE} / \mathrm{E}$ with risk factors was similar to HD; hemoglobin at delivery ( $\geq 11 \mathrm{~g} /$ $\mathrm{dL}), \mathrm{gBMI} \geq 25 \mathrm{~kg} / \mathrm{m}^{2}$ at enrollment and a previous history of $\mathrm{PE} / \mathrm{E}$ were all statistically significant factors for $\mathrm{PE} / \mathrm{E}$. We did not observe an association with employment or maternal age (Table 2). Being on any HAART or any PI at conception or during the 1 st or 2 nd trimester were all associated with increased risk of $P E / E$.

Logistic regression models were run using all variables with $p$ values $\leq 0.2$ which included: maternal age, employment, marital status, previous history of $\mathrm{PE} / \mathrm{E}$, gBMI, trimester of enrollment, ARV at conception, type of ART at conception, ART during 1st and 2nd trimesters (different models for each time period of ART use), and hemoglobin at delivery. Additional models were run forcing CD4 and viral load (to adjust for disease severity) to remain in the model. In the final logistic regression model, HD was significantly associated with women enrolled with a gestational age-adjusted (gBMI) $\geq 25 \mathrm{~kg} / \mathrm{m}^{2}(\mathrm{OR}=3.1 ; 95 \% \mathrm{Cl}: 1.9-5.0)$, maternal age $\geq 35$ years $(\mathrm{OR}=1.8 ; 95 \% \mathrm{Cl}: 1.1-3.2)$, and $\mathrm{Hg} \geq 11 \mathrm{~g} / \mathrm{dL}$ at delivery $(O R=2.1 ; 95 \% \mathrm{Cl}: 1.2-3.6)$. Similarly, PE/E was significantly increased among women enrolled with a gBMl $\geq 25 \mathrm{~kg} / \mathrm{m}^{2}(\mathrm{OR}=3.0 ; 95 \% \mathrm{Cl}: 1.5-6.0)$ and $\mathrm{Hg} \geq 11 \mathrm{~g} / \mathrm{dL}$ at delivery $(\mathrm{OR}=2.8 ; 95 \% \mathrm{Cl}: 1.2-6.5)$. A history of $\mathrm{PE} / \mathrm{E}$ in previous pregnancies was an independent risk factor increasing the risk of PE/E 6.7 times (95\% Cl: 1.8-25.5) compared to those without a history of PE/E (Table 3). Being on HAART at conception was associated with a PE/E in adjusted models $(\mathrm{OR}=2.3 ; 95 \% \mathrm{Cl}: 1.1-4.9)$. Forcing $\mathrm{CD} 4$ and viral load (at enrollment or at the time of delivery) into the model had no impact on the final models.

\section{Discussion}

In this study of HIV-infected pregnant women, we found the prevalence of $\mathrm{HD}$ and $\mathrm{PE} / \mathrm{E}$ was $4.8 \%$ and $2.3 \%$, respectively. 
Table 1 Demographic and clinical characteristics of the study population.

\begin{tabular}{|c|c|c|c|c|}
\hline Variable & Stratification & Total $N(\%)^{a}$ & $\mathrm{HD}^{\mathrm{b}}$ by row stratification $N(\%)$ & $p^{c}$ \\
\hline \multirow[t]{6}{*}{ Country of residence } & Argentina & $377(24.9)$ & $14(3.7)$ & 0.04 \\
\hline & Brazil & $945(62.5)$ & $49(5.2)$ & \\
\hline & Peru & $69(4.5)$ & $2(2.9)$ & \\
\hline & Mexico & $42(2.8)$ & 0 & \\
\hline & Jamaica & $37(2.4)$ & $2(5.4)$ & \\
\hline & Bahamas & $43(2.8)$ & $6(14.0)$ & \\
\hline \multirow[t]{3}{*}{ Maternal age at enrollment (yrs) } & $<20$ & $99(6.6)$ & $2(2.0)$ & 0.04 \\
\hline & $20-34$ & $1176(77.7)$ & $52(4.4)$ & \\
\hline & $\geq 35$ & $238(15.7)$ & $19(8.0)$ & \\
\hline \multirow[t]{4}{*}{ Race } & White & $703(57.8)$ & $27(3.8)$ & 0.21 \\
\hline & Black & $316(26.0)$ & $20(6.3)$ & \\
\hline & Mestizo/other & $196(13.7)$ & $13(6.6)$ & \\
\hline & Missing & 298 & 13 & \\
\hline \multirow[t]{3}{*}{ Maternal education } & $0-6$ & $473(31.1)$ & $24(5.1)$ & 0.49 \\
\hline & $7-12$ & $958(63.3)$ & $43(4.5)$ & \\
\hline & $>12$ & $82(5.4)$ & $6(7.3)$ & \\
\hline \multirow[t]{2}{*}{ Gainfully employed } & Yes & $399(26.4)$ & $27(6.8)$ & 0.04 \\
\hline & No & $1114(73.6)$ & $46(4.1)$ & \\
\hline \multirow[t]{2}{*}{ Marital status } & Married/partner & $1103(72.9)$ & $61(5.5)$ & 0.05 \\
\hline & Single/prev married & $410(27.1)$ & $12(2.9)$ & \\
\hline \multirow{2}{*}{ Previous hx of $\mathrm{PE} / \mathrm{E}^{\mathrm{d}}$} & Yes & $20(1.3)$ & $3(15.0)$ & 0.07 \\
\hline & No & $1493(98.7)$ & $70(4.7)$ & \\
\hline \multirow[t]{2}{*}{ Gravida } & 1 & $211(13.9)$ & $12(5.7)$ & 0.32 \\
\hline & $>1$ & $1302(86.1)$ & $61(4.7)$ & \\
\hline \multirow[t]{3}{*}{ Multiple gestation } & Yes & $23(1.5)$ & $2(8.7)$ & 0.30 \\
\hline & No & $1478(98.5)$ & $71(4.8)$ & \\
\hline & Missing & 12 & 0 & \\
\hline \multirow[t]{3}{*}{ Tobacco use during pregnancy } & Yes & $372(24.9)$ & $13(3.5)$ & 0.20 \\
\hline & No & $1123(75.1)$ & $58(5.2)$ & \\
\hline & Missing & 18 & 2 & \\
\hline \multirow[t]{3}{*}{ Alcohol use during pregnancy } & Yes & $104(9.1)$ & $5(4.8)$ & 0.80 \\
\hline & No & $1041(90.9)$ & $58(5.2)$ & \\
\hline & Missing & 368 & 10 & \\
\hline \multirow[t]{4}{*}{$\mathrm{gBMl}^{\mathrm{e}}$ at enrollment } & $<20$ & $245(16.4)$ & $4(1.6)$ & $<0.01$ \\
\hline & $20-24$ & $761(51.0)$ & $25(3.3)$ & \\
\hline & $\geq 25$ & $487(32.6)$ & $43(8.8)$ & \\
\hline & Missing & 20 & 1 & \\
\hline \multirow[t]{3}{*}{ Trimester at enrollment } & 1st $(1-12$ wk) & $71(4.7)$ & $7(9.9)$ & 0.10 \\
\hline & 2nd (13-26 wk) & $591(39.1)$ & $30(5.1)$ & \\
\hline & $3 r d(27+w k)$ & $851(56.2)$ & $36(4.2)$ & \\
\hline \multirow[t]{2}{*}{ Maternal diabetes } & Yes & $35(2.3)$ & 0 & 0.41 \\
\hline & No & $1478(97.7)$ & $73(4.8)$ & \\
\hline \multirow[t]{3}{*}{ Creatinine at enrollment } & $\leq 1$ & $1466(99.0)$ & $69(4.7)$ & 0.14 \\
\hline & $>1$ & $14(1.0)$ & $2(14.3)$ & \\
\hline & Missing & 33 & 2 & \\
\hline \multirow[t]{3}{*}{ Hemoglobin at enrollment } & $<11$ & $708(47.7)$ & $26(3.7)$ & 0.04 \\
\hline & $\geq 11$ & $777(52.3)$ & $47(6.0)$ & \\
\hline & $\bar{M}$ issing & 28 & 0 & \\
\hline \multirow[t]{3}{*}{ Hemoglobin at delivery } & $<11$ & $676(45.4)$ & $21(3.1)$ & $<0.01$ \\
\hline & $\geq 11$ & $814(54.6)$ & $52(6.4)$ & \\
\hline & Missing & 23 & 0 & \\
\hline \multirow[t]{4}{*}{ CD4 at enrollment } & $<200$ & $210(14.1)$ & $13(6.2)$ & 0.64 \\
\hline & $200-499$ & $762(51.0)$ & $36(4.7)$ & \\
\hline & $\geq 500$ & $520(34.9)$ & $24(4.6)$ & \\
\hline & $\bar{M}$ issing & 21 & 0 & \\
\hline
\end{tabular}




\begin{tabular}{|c|c|c|c|c|}
\hline Variable & Stratification & Total $N(\%)^{a}$ & $\mathrm{HD}^{\mathrm{b}}$ by row stratification $N(\%)$ & $p^{c}$ \\
\hline \multirow[t]{4}{*}{ CD4 prior to delivery } & $<200$ & $180(12.0)$ & $12(6.7)$ & 0.21 \\
\hline & $200-499$ & $693(46.3)$ & 27 (3.9) & \\
\hline & $\geq 500$ & $625(41.7)$ & $34(5.4)$ & \\
\hline & $\bar{M}$ issing & 15 & 0 & \\
\hline \multirow[t]{4}{*}{$\mathrm{VL}^{f}$ at enrollment } & $<1000$ & $951(63.7)$ & $48(5.0)$ & 0.93 \\
\hline & $1000-10,000$ & $277(18.6)$ & $13(4.7)$ & \\
\hline & $\geq 10,000$ & $265(17.7)$ & $12(4.5)$ & \\
\hline & Missing & 20 & 0 & \\
\hline \multirow[t]{4}{*}{$\mathrm{VL}^{\mathrm{f}}$ at delivery } & $<1000$ & $1192(79.4)$ & $62(5.2)$ & 0.34 \\
\hline & $1000-10,000$ & $184(12.3)$ & $5(2.7)$ & \\
\hline & $\geq 10,000$ & $126(8.3)$ & $6(4.8)$ & \\
\hline & Missing & 11 & 0 & \\
\hline \multirow[t]{3}{*}{$\mathrm{ARV}^{\mathrm{g}}$ at conception } & Yes & $310(20.5)$ & $21(6.8)$ & 0.08 \\
\hline & No & 1199 (79.5) & $52(4.3)$ & \\
\hline & Missing & 4 & & \\
\hline \multirow[t]{3}{*}{ Type ARV at conception } & Any PI/HAART & $294(19.5)$ & $21(7.1)$ & 0.04 \\
\hline & Some $\mathrm{ARV}^{\mathrm{h}}$ or None & $1251(80.5)$ & $52(4.3)$ & \\
\hline & Missing & 4 & 0 & \\
\hline \multirow[t]{2}{*}{ ARV during 1st trimester } & Any PI/HAART & $362(23.9)$ & $24(6.6)$ & 0.07 \\
\hline & Some ARV or None & $1151(76.1)$ & $49(4.2)$ & \\
\hline \multirow{2}{*}{ ARV during 2 nd trimester } & Any $\mathrm{PI} / \mathrm{HAART}$ & $1072(70.8)$ & $57(5.3)$ & 0.18 \\
\hline & Some $A R V^{j}$ or None & $441(29.2)$ & $16(3.6)$ & \\
\hline \multirow[t]{2}{*}{ ARV during 3rd trimester } & Any PI/HAART & $1367(90.4)$ & $69(5.0)$ & 0.21 \\
\hline & Some ARV or None ${ }^{k}$ & $146(9.6)$ & $4(2.7)$ & \\
\hline \multirow[t]{2}{*}{ Delivery outcome } & Stillbirth & $30(2.0)$ & $2(6.7)$ & 0.65 \\
\hline & Live birth & $1483(98.0)$ & $71(4.8)$ & \\
\hline
\end{tabular}

a Subjects missing values are not included in percentages.

${ }^{b}$ Hypertensive disorders (HD).

c $p$ Value by Fisher's exact testing.

d Pre-eclampsia/eclampsia (PE/E).

e Gestational age-adjusted body mass index (gBMI).

f Viral load (VL).

g Antiretroviral (ARV).

h 16 subjects on other ARV regimen.

i 29 subjects on other ARV regimen.

j 121 subjects on other ARV regimen.

k 15 subjects not on any ARV.

These percentages are similar to the prevalence of HD and $\mathrm{PE} / \mathrm{E}$ found among pregnant women described in some Latin America countries. ${ }^{14,15}$ Data from the World Health Organization (WHO) Antenatal Care Trial, which included more than 39,000 pregnant women (with unknown HIV status) from Argentina, Cuba, Saudi Arabia and Thailand described $\mathrm{PIH}$ in $7.0 \%$ and PE/E in 2.2\%. ${ }^{14}$ In Brazil, a study with almost 5000 pregnant women with unknown HIV status, enrolled between 1991 and 1995, showed that 3.5\% develop PIH and $2.3 \%$ develop PE/E. ${ }^{15}$

In this cohort, some risk factors for PE and HD were the same described for HIV-uninfected population such as older maternal age, ${ }^{16,17}$ a previous history of $\mathrm{PE} / \mathrm{E},{ }^{18,19}$ and being overweight. ${ }^{20,21}$ Several abnormalities associated with the development of PE such as lower plasma volume, activation of complement system, hyperferritinemia, insulin resistance and metabolic syndrome are also more prevalent among overweight or obese uninfected patients. ${ }^{22-26} \mathrm{Fu}$ thermore, overweight has been associated with oxidative stress consisting of an imbalance of lipid metabolism and an inflammatory state that is also associated with PE. ${ }^{27}$ As almost $50 \%$ of the patients in this study were enrolled during the 3rd trimester of pregnancy we cannot disregard the fact that the increased weight can also be related to fluid retention. In general, reduction of weight in an overweight or obese women prior to conception has been shown to reduce $P E$ and improve other health outcomes ${ }^{28,29}$ and should be also emphasized to HIV-infected women.

Higher hemoglobin among patients with PE/E and HD is expected and explained by the hemoconcentration caused by failure to increase the plasma volume during pregnancy, which is characteristic of PE. Usually, pregnant women start the expansion of plasma volume around the 7th week of gestation and this reaches a plateau around 32 weeks. ${ }^{30}$ During pregnancy, uninfected women increase their plasma volume by almost $45 \%$ but this increase is $50 \%$ lower for those with PE/E. ${ }^{31,32}$ Failure to increase the plasma volume during pregnancy leads to hemoconcentration, a higher vascular resistance with a consequently decrease in uteroplacental flow and higher odds for perinatal complications. ${ }^{33}$

The role of HIV-infection in the development of preeclampsia is controversial. Wimalasundera et al. found a 
Table 2 Bivariate analyses of all hypertensive disorders (HD) and preeclampsia and eclampsia (PE/E) by covariates of interest.

\begin{tabular}{|c|c|c|c|c|c|c|c|}
\hline Covariates & Strata & $\begin{array}{l}\mathrm{HD} \\
N=73(\%)\end{array}$ & $\begin{array}{l}\text { No HD } \\
N=1440 \text { (\%) }\end{array}$ & $p^{a}$ & $\begin{array}{l}\mathrm{PE} / \mathrm{E} \\
N=35(\%)\end{array}$ & $\begin{array}{l}\text { No PE/E } \\
N=1478 \text { (\%) }\end{array}$ & $p^{a}$ \\
\hline \multirow{3}{*}{ Maternal age } & $<20$ & $2(2.0)$ & $97(98.0)$ & 0.04 & $1(1.0)$ & $98(99.0)$ & 0.09 \\
\hline & $20-34$ & $52(4.4)$ & $1124(95.6)$ & & $24(2.0)$ & $1152(98.0)$ & \\
\hline & $\geq 35$ & $19(8.0)$ & $219(92.0)$ & & $10(4.2)$ & $228(95.8)$ & \\
\hline \multirow[t]{2}{*}{ Gainfully employed } & Yes & $27(6.8)$ & $372(93.2)$ & 0.04 & $13(3.2)$ & $386(96.7)$ & 0.17 \\
\hline & No & $46(4.1)$ & $1068(95.9)$ & & $22(2.0)$ & $1092(98.0)$ & \\
\hline \multirow[t]{2}{*}{ Marital status $^{\mathrm{b}}$} & Married & $61(5.5)$ & $1042(94.5)$ & 0.05 & $27(2.5)$ & $1076(97.5)$ & 0.57 \\
\hline & Single & $12(2.9)$ & $398(97.1)$ & & $8(2.0)$ & $402(98.0)$ & \\
\hline \multirow[t]{2}{*}{ Previous history of PE/E } & Yes & $3(15.0)$ & $17(85.0)$ & 0.07 & $3(15.0)$ & $17(85.0)$ & 0.01 \\
\hline & No & $70(4.7)$ & $1423(95.3)$ & & $32(2.1)$ & $1461(97.9)$ & \\
\hline Gestational age adjusted & $<20$ & $4(1.6)$ & $241(98.4)$ & $<0.01$ & $2(0.8)$ & $243(99.2)$ & $<0.01$ \\
\hline \multirow[t]{2}{*}{ BMI at enrollment (gBMI) } & $20-24$ & $25(3.3)$ & $736(96.7)$ & & $12(1.6)$ & $749(98.4)$ & \\
\hline & $\geq 25$ & $43(8.8)$ & $444(91.2)$ & & $20(4.1)$ & $467(95.9)$ & \\
\hline \multirow[t]{3}{*}{ Trimester $^{\complement}$ at enrollment } & $\overline{1 s t}$ & 7 (9.9) & $64(90.1)$ & 0.10 & $4(5.6)$ & $67(94.4)$ & 0.12 \\
\hline & 2 nd & $30(5.1)$ & $561(94.9)$ & & $15(2.5)$ & $576(97.5)$ & \\
\hline & $3 r d$ & $36(4.2)$ & $815(95.8)$ & & $16(1.9)$ & $835(98.1)$ & \\
\hline \multirow[t]{2}{*}{ Creatinine at enrollment } & $\leq 1$ & $69(4.7)$ & $1397(95.3)$ & 0.14 & $33(2.2)$ & $1433(97.8)$ & 0.28 \\
\hline & $>1$ & $2(14.3)$ & $12(85.7)$ & & $1(7.1)$ & $13(92.9)$ & \\
\hline \multirow[t]{2}{*}{ Hemoglobin at enrollment (g/dL) } & $<11$ & $26(3.7)$ & $682(96.3)$ & 0.04 & $10(1.4)$ & $698(98.6)$ & 0.03 \\
\hline & $\geq 11$ & $47(6.1)$ & 730 (93.9) & & $25(3.2)$ & $752(96.8)$ & \\
\hline \multirow[t]{2}{*}{ Hemoglobin after delivery (g/dL) } & $<11$ & $21(3.1)$ & 655 (96.9) & $<0.01$ & $8(1.2)$ & $668(98.8)$ & 0.01 \\
\hline & $\geq 11$ & $52(6.4)$ & $762(93.6)$ & & $27(3.3)$ & 787 (96.7) & \\
\hline \multirow[t]{2}{*}{ Type of $A R T^{d}$ at conception } & HAART & $21(7.1)$ & 273 (92.9) & 0.04 & $13(4.4)$ & $281(95.6)$ & $<0.01$ \\
\hline & No HAART & $52(4.3)$ & 1167 (95.7) & & $22(1.8)$ & $1197(98.2)$ & \\
\hline \multirow[t]{2}{*}{ ART: 1st trimester } & HAART & $24(6.6)$ & $338(93.4)$ & 0.07 & $13(3.6)$ & 349 (96.4) & 0.07 \\
\hline & No HAART & $49(4.2)$ & 1102 (95.7) & & 22 (1.9) & $1129(98.1)$ & \\
\hline
\end{tabular}

All covariates with $p<.2$ considered in logistic regression modeling.

a $p$ Value obtained using Fisher's exact testing.

b Marital status divided into Married (includes living with partner) and Single (includes divorced and widowed).

c Trimester of pregnancy defined as follows: 1st (1-12 weeks gestation), 2nd (13-26 weeks gestation), 3rd (27+ weeks gestation).

d Type of antiretroviral therapy (ART) divided into: HAART (including use of any PI) and no HAART (includes any mono, dual, triple therapy and no therapy).

lower rate of PE among untreated HIV-infected women ${ }^{8}$ when compared to uninfected women or HIV-infected on treatment. More recently, Kalumba et al. ${ }^{34}$ described a lower rate of HIV-infection among women with preeclampsia when compared with women without preeclampsia. Several studies show no difference in the rates of PE between HIV-uninfected and HIV-infected women treated with HAART ${ }^{35,36}$ or even a lower rate of PE among HIVinfected treated when compared to uninfected women. ${ }^{10}$

We observed that the use of HAART at conception was a risk factor for PE/E. This is in agreement with two other studies which showed that the use of HAART prior to pregnancy increase the odds for hypertension and PE. ${ }^{9,37}$ Lack of stratification with the use of HAART in relation to pregnancy could explain the discrepancy among studies. Some authors suggest that immune restoration, secondary to the use of HAART could be involved in the development of PE. ${ }^{8}$ It has been shown that low levels of retinol are correlated with PE and it was suggested that a mechanism of HAART-induced PE could be a reduction of serum retinol concentrations due to hepatotoxicity. ${ }^{38,39}$ HIV-infected pregnant women using HAART present a shift towards a

Table 3 Final logistic regression model. ${ }^{\mathrm{a}}$

\begin{tabular}{lll}
\hline Covariates & Final model-HD & Final model-PE/E \\
& OR $(95 \% \mathrm{Cl})$ & OR $(95 \% \mathrm{Cl})$ \\
\hline $\mathrm{gBMl}: \geq 25 \mathrm{~kg} / \mathrm{m}^{2} \mathrm{vs.}<25 \mathrm{~kg} / \mathrm{m}^{2}$ & $3.1(1.9-5.0)$ & $3.0(1.5-6.0)$ \\
Hg at L\&D: $\geq 11 \mathrm{~g} / \mathrm{dL}$ vs. $<11 \mathrm{~g} / \mathrm{dL}$ & $2.1(1.2-3.6)$ & $2.8(1.2-6.5)$ \\
\hline Maternal age: $\geq 35 \mathrm{yr}$ vs. $<35 \mathrm{yr}$ & $1.8(1.1-3.2)$ & $\mathrm{NA}$ \\
\hline ARV type at conception: HAART vs. non-HAART & $\mathrm{NA}$ & $2.3(1.1-4.9)$ \\
Previous history of PE/E: Yes vs. No & $\mathrm{NA}$ & $6.7(1.8-25.5)$ \\
\hline \hline
\end{tabular}

HD - hypertensive disorders; PE/E - preeclampsia/eclampsia; NA - not applicable.

a Forcing CD4 and viral load at enrollment or at L\&D had no impact on the final models. 
Th1 cytokine production while, in a healthy pregnancy, a Th2 response is predominantly observed. ${ }^{40,41}$ Also a Th1 immune response is observed in PE. ${ }^{42}$ It is possible that HIVinfected pregnant women on HAART, especially those with long exposure to therapy, would have a blunted shift of Th2 cytokines increasing the predisposition to eclampsia.

The current pathophysiological mechanism of preeclampsia involves poor placental perfusion and the excessive release of inflammatory factors that damage the mother's vascular endothelial cells, resulting in systemic hypertension and endothelial dysfunction. ${ }^{43}$ In addition, regarding HIV-infected patients, some ART has been associated with endothelial dysfunction and CVD. ${ }^{44}$ Nevertheless, Torriani et al. (2008), ${ }^{45}$ comparing three different randomized ARV regimens among HIV-infected naïve individuals, in order to evaluate the effect of these ARV on endothelial function, noticed rapid improvement of endothelial function after ARV administration. Savvidou et al. (2011) evaluated the uteroplacental circulation by Doppler ultrasound of HIV-infected and non-infected pregnant women in the first trimester of gestation - a probable early biomarker to predict PE - with the aim to assess the degree of placental invasion. They found normal placental perfusion among HIV-infected women, with uncomplicated pregnancies, receiving and not receiving ARV regimen. Although, these authors state that the majority of women presented CD4 cell count $>250$ cells $/ \mathrm{mm}^{3}$ and, therefore, they could not exclude problems of uteroplacental perfusion in women with a compromised immune system. ${ }^{46}$

Among the strengths of this study are the large size of the cohort, enrollment of study participants across several countries in Latin America and the Caribbean and the prospective collection of data with a very low rate of loss to follow-up. One of the limitations of this study is that we did not have information regarding adherence to ART and, also, we did not collect data on the duration of ART prior to the current pregnancy.

Strategies to prevent HD among HIV-infected women should include preconception counseling to high-risk women who are planning a pregnancy. It would also be interesting to compare risk of $\mathrm{HD}$ between women on treatment longer before pregnancy with normalization of CD4+ T-cell counts with those who started HAART during pregnancy but have already a lower CD4+ T-cell count.

The findings of this study showing a significant association of $B M I \geq 25$, a history of $P E / E$ in previous pregnancies and hemoconcentration with PE are consistent with the literature regarding risk factors for $P E$ and $H D$ in uninfected pregnant women. Being on HAART at conception was associated with a 2.3 times risk of developing PE/E during pregnancy.

\section{Acknowledgments}

We would like to thank all the patients who agreed to take part on this study.

Funding: Supported by Eunice Kennedy ShriverNational Institute of Child Health and Human Development, Bethesda, Maryland, USA (NICHD) Contract \# N01-HD-3-3345 (2002-2007) and by NICHD Contract \# HHSN267200800001C (NICHD Control \#: N01-HD-8-0001) (2007-2012).
NICHD was involved in all aspects of study design, data analysis and interpretation, and manuscript writing/ editing.

\section{NICHD International Site Development Initiative: Perinatal/LILAC Protocol}

Principal investigators, co-principal investigators, study coordinators, coordinating center representatives, and NICHD staff include: Argentina: Buenos Aires: Marcelo H. Losso, Irene Foradori, Alejandro Hakim, Erica Stankievich, Silvina Ivalo (Hospital General de Agudos José María Ramos Mejía); Brazil: Belo Horizonte: Jorge A. Pinto, Victor H. Melo, Fabiana Kakehasi, Beatriz M. Andrade (Universidade Federal de Minas Gerais); Caxias do Sul: Rosa Dea Sperhacke, Nicole Golin, Sílvia Mariani Costamilan (Universidade de Caxias do Sul/Serviço Municipal de Infectologia); Nova Iguacu: Jose Pilotto, Luis Eduardo Fernandes, Gisely Falco (Hospital Geral Nova de Iguacu - HIV Family Care Clinic); Porto Alegre: Rosa Dea Sperhacke, Breno Riegel Santos, Rita de Cassia Alves Lira (Universidade de Caxias do Sul/ Hospital Conceição); Rosa Dea Sperhacke, Mario Ferreira Peixoto, Elizabete Teles (Universidade de Caxias do Sul/ Hospital Fêmina); Regis Kreitchmann, Luis Carlos Ribeiro, Fabrizio Motta, Debora Fernandes Coelho (Irmandade da Santa Casa de Misericordia de Porto Alegre); Ribeirão Preto: Marisa M. Mussi-Pinhata, Geraldo Duarte, Adriana A. Tiraboschi Bárbaro, Conrado Milani Coutinho, Fabiana Rezende Amaral, Anderson Sanches de Melo (Hospital das Clínicas da Faculdade de Medicina de Ribeirão Preto da Universidade de São Paulo); Rio de Janeiro: Ricardo Hugo S. Oliveira, Elizabeth S. Machado, Maria C. Chermont Sapia (Instituto de Puericultura e Pediatria Martagão Gesteira); Esau Custodio Joao, Leon Claude Sidi, Maria Leticia Santos Cruz, Maria Isabel Gouvêa, Mariza Curto Saavedra, Clarisse Bressan, Fernanda Cavalcanti A. Jundi (Hospital dos Servidores do Estado); São Paulo: Regina Celia de Menezes Succi, Prescilla Chow (Escola Paulista de Medicina - Universidade Federal de São Paulo); Peru: Lima: Jorge O. Alarcón Villaverde (Instituto de Medicina Tropical "Daniel Alcides Carrión" - Sección de Epidemiología, UNMSM), Carlos Velásquez Vásquez (Instituto Nacional Materno Perinatal), César Gutiérrez Villafuerte (Instituto de Medicina Tropical "Daniel Alcides Carrión" - Sección de Epidemiología, UNMSM); Data Management and Statistical Center: Yolanda Bertucci, Rachel Cohen, Laura Freimanis Hance, René Gonin, D. Robert Harris, Roslyn Hennessey, James Korelitz, Margot Krauss, Sue Li, Karen Megazzini, Orlando Ortega, Sharon Sothern de Sanchez, Sonia K. Stoszek, Qilu Yu (Westat, Rockville, MD, USA); NICHD: George K. Siberry, Rohan Hazra, Lynne M. Mofenson, Jennifer S. Read, Heather Watts (Eunice Kennedy Shriver National Institute of Child Health and Human Development, Bethesda, Maryland, USA).

\section{References}

1. Connor EM, Sperling RS, Gelber R, Kiselev P, Scott G, O'Sullivan MJ, et al. Reduction of maternal-infant transmission of human immunodeficiency virus type 1 with zidovudine 
treatment. Pediatric AIDS Clinical Trials Group Protocol 076 Study Group. N Engl J Med 1994;331:1173-80.

2. Coovadia H. Antiretroviral agents - how best to protect infants from HIV and save their mothers from AIDS. N Engl J Med 2004; 351:289-92.

3. Thorne C, Patel D, Newell ML. Increased risk of adverse pregnancy outcomes in HIV-infected women treated with highly active antiretroviral therapy in Europe. AIDS 2004;18:2337-9.

4. Kourtis AP, Bansil P, McPheeters M, Meikle SF, Posner SF, Jamieson DJ. Hospitalizations of pregnant HIV-infected women in the USA prior to and during the era of HAART, 1994-2003. AIDS 2006;20:1823-31.

5. Kale PL, Costa AJL. Maternal deaths in the city of Rio de Janeiro, Brazil, 2000-2003. J Health Popul Nutr 2009;27: 794-801.

6. Vega CEP, Kahhale S, Zugaib M. Maternal mortality due to arterial hypertension in São Paulo City (1995-1999). Clinics 2007; 62:679-84

7. Lambert JS, Watts DH, Mofenson L, Stiehm ER, Harris DR, Bethel J, et al. Risk factors for preterm birth, low birth weight, and intrauterine growth retardation in infants born to HIVinfected pregnant women receiving zidovudine. Pediatric AIDS Clinical Trials Group 185 Team. AIDS 2000;14:1389-99.

8. Wimalasundera RC, Larbalestier N, Smith JH, de Ruiter A, McG Thom SA, Hughes AD, et al. Pre-eclampsia, antiretroviral therapy, and immune reconstitution. Lancet 2002;360:1152-4.

9. Suy A, Martínez E, Coll O, Lonca M, Palacio M, de Lazzari E, et al. Increased risk of pre-eclampsia and fetal death in HIVinfected pregnant women receiving highly active antiretroviral therapy. AIDS 2006;20:59-66.

10. Mattar R, Amed AM, Lindsey PC, Sass N, Daher S. Preeclampsia and HIV infection. Eur J Obstet Gynecol Reprod Biol 2004;117: $240-1$.

11. Read JS, Cahn P, Losso M, Pinto J, Joao E, Duarte G, et al. Management of human immunodeficiency virus-infected pregnant women at Latin American and Caribbean sites. Obstet Gynecol 2007; 109:1358-67.

12. Centers for Disease Control and Prevention. 1993 revised classification system for HIV infection and expanded surveillance case definition for AIDS among adolescents and adults. MMWR Recomm Rep 1992;41(RR-17):1-19.

13. Calvo EB, Durán P, Longo EN, Mazza C, Gilardon EOA. Evaluación del estado nutricional de ninas, ninos y embarazadas mediante antropometría. 1a ed. Ministerio de Salud de la Nación; 2009. pp. 87-92 http://www.msal.gov.ar/promin/ publications/pdf/manual-nutricion-press.pdf.

14. Villar J, Carroli G, Wojdyla D, Abalos E, Giordano D, Ba'aqeel $\mathrm{H}$, et al. Pre-eclampsia, gestational hypertension and intrauterine growth restriction, related or independent conditions? Am J Obstet Gynecol 2006;194:921-31.

15. Gaio DS, Schmidt MI, Duncan BB, Nucci LB, Matos MC, Branchtein L. Hypertensive disorders in pregnancy: frequency and associated factors in a cohort of Brazilian women. Hypertens Pregnancy 2001;20:269-81.

16. Sultana R, Chen XK, Lee C, Hader J. Outcomes in multiple gestation pregnancies among Canadian women age 35 years and older. Healthc Q 2011;14:22-4.

17. Lamminpaa R, Vehvilainen-Julkunen K, Gissler M, Heinonen S. Preeclampsia complicated by advanced maternal age: a registry-based study on primaparous women in Finland 1997-2008. BMC Pregnancy Childbirth 2012;12:47.

18. Ganesh KS, Unnikrishnan B, Nagaraj K, Jayaram S. Determinants of pre-eclampsia: a case-control study in a District Hospital in South India. Indian J Community Med 2010;35:502-5.

19. Guzman-Juarez W, Avila-Esparza M, Contretas-Solia RE, Levario-Carrillo $M$. Factors associated with gestational hypertension and preeclampsia. Ginecol Obstet Mex 2012;80:461-6.
20. Dennedy MC, Avalos G, O'Reilly MW, O’Sullivan EP, Dunne FP. The impact of maternal obesity on gestational outcomes. Ir Med J 2012;105:23-5.

21. Mandal D, Manda S, Rakshi A, Dey RP, Biswas SC, Banerjee A. Maternal obesity and pregnancy outcome: a prospective analysis. J Assoc Physicians India 2011;59:486-9.

22. Aardenburg R, Spaanderman ME, Ekhart TH, van Eijndhoven HW, van der Heijden OW, Peeters LL. Low plasma volume following pregnancy complicated by pre-eclampsia predisposes for hypertensive disease in a next pregnancy. BJOG 2003;110:1001-6.

23. Lynch AM, Eckel RH, Murphy JR, Gibbs RS, West NA, Giclas PC, et al. Prepregnancy obesity and complement system activation in early pregnancy and the subsequent development of preeclampsia. Am J Obstet Gynecol 2012;206. 428.e1-428.e8.

24. Raman L, Pawashe AB, Yasodhara P. Hyperferritinemia in pregnancy induced hypertension and eclampsia. J Postgrad Med 1992;38:65-7.

25. Lu J, Zhao YY, Qiao J, Zhang HJ, Ge L, Wei Y. A follow-up study of women with a history of severe preeclampsia: relationship between metabolic syndrome and PE. Chin Med $J$ (Engl) 2011;124:775-9.

26. Hauth JC, Clifton RG, Roberts JM, Myatt L, Spong CY, Leveno KJ, et al. Maternal insulin resistance and preeclampsia. Am J Obstet Gynecol 2011;204. 327.e1-327.e6.

27. Zavalza-Gomez AB. Obesity and oxidative stress: a direct link to preeclampsia? Arch Gynecol Obstet 2011;283:415-22.

28. Thangaratinam S, Rogozinska E, Jolly K, Glinkowski S, Roseboom T, Tomlinson JW, et al. Effects of interventions in pregnancy on maternal weight and obstetric outcomes: meta-analysis of randomised evidence. BMJ 2012;344: e2088.

29. Mostello D, Jen Chang J, Allen J, Luehr L, Shyken J, Leet T. Recurrent preeclampsia: the effect of weight change between pregnancies. Obstet Gynecol 2012;116:667-72.

30. Bridges EJ, Womble S, Wallace M, McCartney J. Hemodynamic monitoring in high-risk obstetrics patients, I: expected hemodynamic changes in pregnancy. Crit Care Nurse 2003;23: $53-62$.

31. Hytten F. Blood volume changes in normal pregnancy. Clin Haematol 1985;14:601-12.

32. Silver HM, Seebeck M, Carlson R. Comparison of total blood volume in normal, preeclamptic, and nonproteinuric gestational hypertensive pregnancy by simultaneous measurement of red blood cell and plasma volumes. Am J Obstet Gynecol 1998; 179:87-93.

33. Yang JM, Yang YC, Wang KG. Central and peripheral hemodynamics in severe preeclampsia. Acta Obstet Gynecol Scand 1996;75:120-6.

34. Kalumba VMS, Moodley J, Naidoo TD. Is the prevalence of preeclampsia affected by HIV/AIDS? A retrospective case-control study. Cardiovasc J Afr 2013;24:24-7.

35. Conde-Agudelo A, Villar J, Lindheimer M. Maternal infection and risk of preeclampsia: systematic review and metaanalysis. Am J Obstet Gynecol 2008;198:7-22.

36. Boyajian T, Shah PS, Murphy KE. Pregnant women receiving HAART: a matched cohort study. J Obstet Gynaecol Can 2012;34:136-41.

37. Parekh N, Ribaudo H, Souda S, Chen J, Mmalane M, Powis K, et al. Risk factors for very preterm delivery and delivery of very-small-for-gestational-age infants among HIV-exposed and HIV-unexposed infants in Botswana. Int J Gynaecol Obstet 2011;115:20-5.

38. Zhang C, Williams MA, Sanchez SE, King IB, Ware-Jauregui S, Larrabure G, et al. Plasma concentrations of carotenoids, retinol, and tocopherols in preeclamptic and normotensive pregnant women. Am J Epidemiol 2001;153:572-80. 
39. Mawson AR. Effects of antiretroviral therapy on occurrence of pre-eclampsia. Lancet 2003;361:347-8.

40. Fiore S, Newell ML, Trabattoni D, Thorne C, Gray L, Savasi V, et al. Antiretroviral therapy-associated modulation of Th1 and Th2 immune responses in HIV-infected pregnant women. J Reprod Immunol 2006;70:143-50.

41. Jonsson Y, Matthiesen L, Berg G, Emerudh J, Nieminen K, Ekerfelt $C$. Indications of an altered immune balance in preeclampsia: a decrease in in vitro secretion of IL-5 and IL-10 from blood mononuclear cells an in blood basophil counts compared with normal pregnancy. J Reprod Immunol 2005; 66:69-84.

42. Laresgoiti-Servitje E, Gomez-Lopez N, Olson DM. An immunological insight into the origins of pre-eclampsia. Hum Reprod Update 2010;16:510-24.
43. Fei X, Hongxiang Z, Qi C, Daozhen C. Maternal plasma levels of endothelial dysfunction mediators including AM, CGRP, sICAM-1 and tHcy in pre-eclampsia. Adv Clin Exp Med 2012;21:573-9.

44. Gupta SK, Shen C, Moe SM, Kamendulis LM, Goldman M, Dubé MP. Worsening endothelial function with efavirenz compared to protease inhibitors: a 12-month prospective study. PLoS One 2012;7:e45716.

45. Savvidou MD, Samuel MI, Akolekar R, Poulton M, Nicolaides KH. First trimester maternal uterine artery Doppler examination in HIV-positive women. HIV Med 2011;12:632-6.

46. Torriani FJ, Komarow L, Parker RA, Cotter BR, Currier JS, Dubé MP, et al. Endothelial function in HIV-infected antiretroviral naïve subjects before and after starting potent antiretroviral therapy: AIDS Clinical Trials Group Study 5152s. J Am Coll Cardiol 2008;52:569-76. 